\title{
Disturbed Lands Reclamation Statement in the Territory of the Mokhovsky Coal Mine
}

\author{
Natalia Stenina ${ }^{1,2}$, Oksana Ivina $^{2}$, Marina Yakovchenko ${ }^{1}$, and Gennady Lebedev ${ }^{2}$ \\ ${ }^{1}$ Kuzbass State Agricultural Academy, 5 Markovtseva Street, Kemerovo, 650056, Russia \\ ${ }^{2}$ T.F. Gorbachev Kuzbass State Technical University, 28 Vesennyaya Street, Kemerovo, 650000, Rus- \\ sia
}

\begin{abstract}
The national project "Ecology" sets to bring up to date the ecological policy of the environment-geared laws of the Russian Federation which must preserve biodiversity and afford the involvement of all participants in the process. Revegetation, as part of the program, sets to restore disturbed lands to a condition suitable for their use in the national economy and prevent their anthropogenic impact on the adjacent areas. The quality of reclamation works is not always at an adequate level, which creates difficulties in the remediated lands development. This is a consequence of insufficient information at the design stage, specifically data on the composition and properties of the soil cover and worked-out rock mass, lack of special technical support for the implementation of remediation measures at the proper level, the landscape of the deposit is not taken into account during the work with disturbed soils. Intensive use of the studied territories of the Sartakinsky, Karakansky and Mokhovsky fields both in agricultural and mining industries led to changes in the natural biocenos. This paper presents the study of soil-agrochemical characteristics (granulometric and structural structure of soil, the humus content, hydrogen index, the content of food elements, hydrolytic acidity, the sum of absorbed bases, absorption capacity, etc.) on different genetic horizons of zonal soils of Mokhovsky coal mine, and specifically unbroken soils of Mokhovsky, Sartakinsky and Karakansky fields on possibility of their use at carrying out of biological reclamation.
\end{abstract}

\section{Introduction}

The natural fund of the Kemerovo region is represented by unique ecosystems formed in the landscape of the Kuznetsk Basin under the influence of different natural and climatic zones. Mining enterprises operating on the territory of Kuzbass, implementing the program of development of the coal industry of the Russian Federation are constantly increasing their production capacity, having a man-caused impact on natural ecosystems, which leads to the violation of biodiversity up to complete eradication. The negative impact of the mining industry has been the focus of specialists' attention for many years. Environmental problems associated with coal mining include coal mine accidents, ground subsidence, formation of unstable slopes subject to slippage and erosion, water damage, mining waste disposal and air pollution. These are either environmental pollution or landscape change. Disturbed land from both surface and underground mining can also lead to serious problems with water quality. 
Measures to prevent degradation of the biosphere focus on a high level of environmental safety in the coal industry and aim not only at preserving the remaining natural ecosystems but also at restoring the prevailing open cast mining method destroyed by activities. Quarrying leads to the complete destruction of natural biocenos by transferring a mixture of overburden and host rocks to the surface. Without reclamation works, such areas are subject to erosion processes, which lead to degradation of adjacent land areas, these soils are heavily contaminated with toxic substances and have disturbed water and gas exchange.

\section{Materials and Methods}

Restoration of the ability to transform rock into soil, reproduction of natural consortia, selfpurification of soil are the main tasks of restoration of biological diversity. Preservation of biodiversity is one of the directions of implementation of the National Project "Ecology", in which Kuzbass actively joined last year, which is important for sustainable development of the mining industry in the region. The problems connected with mining and subsequent restoration of the landscape are of global, national and local nature. Biological diversity is the main natural resource for progressive evolutionary development of human civilization. Biodiversity sets to ensure the sustainability of ecosystems and the biosphere as a whole. In Siberia, for many mining enterprises, it is a very urgent task to use the natural potential of the areas to restore disturbed lands and to change the order of reclamation due to favorable circumstances. Fundamental question is reclamation of the territories which have already passed a stage of restoration of vegetation. As practice shows, the implementation of restoration activities in areas of effective overgrowth gives worse results than those created by nature during tens of years, because the disturbed lands return to the original state of disturbance and everything starts over again [1].

In the Kuznetsk coal basin there are often areas of dumps with self-infestation, especially on dumps worked out 30 or more years ago. However, it should be recognized that structural and functional characteristics of plant communities may vary significantly not only in different natural zones, but also within the same dump. The reason is the uneven ecological conditions of man-made habitats, where the main limiting factor for plants is moisture retention in the substrate of dumps, which in turn depends on a whole set of conditions: the composition and properties of rocks, the degree of rockiness of the surface, the exposure and steepness of slopes, the form of meso- and micro-relief, the amount of precipitation in summer and winter. It is impossible to assess the impact of different open-cast coal mining technologies in terms of the degree of ecosystem degradation, as it is in all cases equally complete. Only natural or artificial regeneration of the vegetation cover on the disturbed lands reveals the difference. The criterion for assessment of the environmental impact of surface mining operations should be considered the possibility of vegetation cover regeneration on disturbed lands. The use of vegetation cover provides a cost-effective and environmentally sustainable method of stabilizing and recultivating waste such as mining operations. Positive results of biological reclamation by perennial grasses of various species composition, conifers of trees, bushes on lands disturbed during coal mining have been noted. Plant communities have a direct impact on the duration of self-rehabilitation of land cover and take on average from 5 to $10-15$ years. The multilevel structure obtained in this way well protects the land from deflation and erosion processes, strengthening the surface soils to prevent wind dust removal. In particular, there is a positive experience in creating multispecies forest plantations at the dumps of Krasnogorsky surface mine and Topkinsky Cement enterprise of Solomensky limestone deposit, at the dumps of Kedrovsky coal mine willows and poplars are planted. [2,3].

The high stability of mountain ash development in the Krasnoyarsk region, the Borodinsky section and the possibility of using this species for landscaping and improvement of adjacent areas were established. Positive trends in the development of pine forest at internal 
dumps were also noted in this section. Ecological conditions of overburden dumps of coal deposits in the Kemerovo region are favorable for the growth of ordinary pine trees $[4,5]$. Restoration of the area of 32.5 ha of Abakansky coal mine has been achieved $100 \%$ as a result of the forest reclamation works. It is expected that reclamation of coal mines using conifers will restore the potential of these lands to provide forest ecosystems such as timber production, atmospheric carbon sequestration, wildlife habitat formation to a greater extent than traditional restoration methods [6].

From origin, composition, structure and properties of soil-forming rocks the speed of formation of soil profile changes as biochemical processes of soil formation depend on constantly changing topography of dumps surface and natural and climatic conditions of deposits $[7,8]$. Rock, extracted from coal sections of Kuzbass, gradually replaces agricultural lands and forest areas. The assessment of the ecology of disturbed lands has shown that it is impossible to fully restore the lost soil function, as the formation of organo-accumulative horizon is extremely slow. This fact is confirmed by studies conducted by soil scientists of the Kemerovo region on reclaimed lands during 40 years with a maximum result of $90 \%$ and average fertility value of about $30 \%[9,10]$.

It is expedient to conduct ecological monitoring of the disturbed lands of the Kemerovo region, where the soil and ecological condition of the reclaimed areas is connected with the specifics of mining operations and logistics of quarry cargo transportation. In addition to the direct impact of open-pit mining operations on natural complexes, which is catastrophic in nature, indirect impact is also significant. Indirect impacts cause the degradation of phytocoenosis in a significant area adjacent to development. Indicators for estimating such changes are species composition mutations and declining biological productivity. The average area of disturbed land in the region is about 1000 ha/year, most of which is overburden heaps. In 2018, 6.8 thousand hectares of land in Kuzbass were disturbed from 10.66 thousand hectares throughout Russia by coal enterprises (64.2\%). At the same time, only 107 hectares were reclaimed, which made up 1.6 percent of the disturbed lands for the year. The total indicator of reclamation performed in 2018 was twice lower than in 2017, when it was performed on 227 hectares, and lower than in 2016 - 153 hectares. Large areas of land have been depleted by mining activities and remain unused, hampering agricultural, social and economic sustainable development. If no measures are taken to reduce the negative impact and terms of use of rehabilitated lands, taking into account the possibility of second violations, in the near future all land plots in the Kemerovo region will be used by coal mining [11]. A comprehensive approach is required, not only to restore land resources and restore damaged ecosystems, but also to create habitats and restore biodiversity [12].

A number of applied research, method development and technical solutions are currently being carried out using intelligent machine technology presented by robotic platforms to accurately assess and monitor biodiversity in lands disturbed by mining operations. The development of a robotic platform equipped with a system of specialized sensors and probes for ex-press monitoring of soil composition will reduce time and increase productivity both at agricultural enterprises and at coal mines during remediation activities. Most traditional methods of determining these indicators are labour-intensive and time-consuming. Rapid monitoring systems allow effective application of co-modern technologies without adaptation to specific conditions and in conditions of heterogeneous soils of coal deposits. The use of such equipment significantly increases production efficiency and optimizes costs. As a whole results of tests of a platform will allow to reveal possibility of application of robotics at monitoring of soils and definition of their structure [13].

Mining and geological structure of the deposits, insufficient amount of nutrients in the rocks, instability of water and thermal conditions have a negative impact on the formation of vegetation cover on overburden heaps. Only purposeful formation of favorable root layer will allow to create necessary ecological conditions for restoration of disturbed ecosystems as 
formation of woody vegetation on technogenic landscapes of forest-steppe zone of Kuzbass does not promote development of soil formation processes on disturbed territories. As a result, a closed, very shady stand grows. Grass layer and undergrowth are not formed in it, adolescence is underdeveloped, and the species composition is represented by few, mainly weed species of grass.

The purpose of this study was to study the agrochemical characteristics of the Mossy coal mine zone soils for the possibility of their use in carrying out activities to restore biological diversity. The research tasks included: 1) to study soil and climatic conditions of location of Sartakinsky, Karakansky and Mokhovsky fields of the Mokhovsky coal mine; 2) to study for each field the soil horizons and determine the types of soils; 3 ) to study the physicochemical characteristics of the studied areas to determine the quality of land; 4) to consider the possibility of using the studied land for biological reclamation.

\section{Results and Discussions}

The objects of research were the Sartakinsky, Karakansky and Mokhovsky fields of the Mokhovsky coal mine. The studied physical and chemical characteristics of soils are presented in Figures 1-5. The $\mathrm{pH}$ level is an indicator of the availability of elements for plant nutrition and allows us to estimate the root and leaf nutrition. To control mineral nutrition of plants quantitative characteristics of mineral elements included in the soil were determined. In addition to making up for the lack of basic elements - nitrogen, phosphorus and potassium, the soil should have a balanced composition for the intake of a number of mineral elements of plant nutrition, ensuring normal growth and development, immunity to diseases and pests, resistance to adverse conditions. The granulometric composition of soil was established to assess the level of fertility, functionality, a number of physical, chemical and biological properties. The level of humus at different horizons of the soil cover was assessed.

Analysis of physical and chemical characteristics of Sartakinsky field. The particle size distribution of soil in the Sartakinsky field of section No. 3 is represented by a heavy loam. The content of fine sand fraction is $19.9 \%$, coarse dust is 20.2 , silt is $26.3 \%$. The size of structural units of the upper horizon was from 5 to $0.25 \mathrm{~mm}$. The dust is contained in only $8 \%$ of the mass of air-dry soil. The share of lumpy fraction $(>10 \mathrm{~mm})$ is $9.4 \%$.

The content of humus in the $0-60 \mathrm{~cm}$ layer is $6.4-5.2 \%$, with its depth in the soil drops sharply. Horizons of washout are poor in nutrients. Soils in which these horizons are strongly developed tend to have low fertility.

Index of soil solution of upper horizon $\mathrm{pH}=5.2$, slightly acidic, below - average acidic throughout the profile. Absorption capacity throughout the profile is characterized as high: $51-37 \mathrm{mg} / 100 \mathrm{~g}$ of soil. Absorption capacity is mainly composed of calcium and magnesium (in the upper horizon their sum is $45 \mathrm{mg}$ eq/100 g). Hydrolytic acidity is high throughout the soil profile from 5.82 to $6.84 \mathrm{mg}$ eq/100 $\mathrm{g}$ in bedrock. 

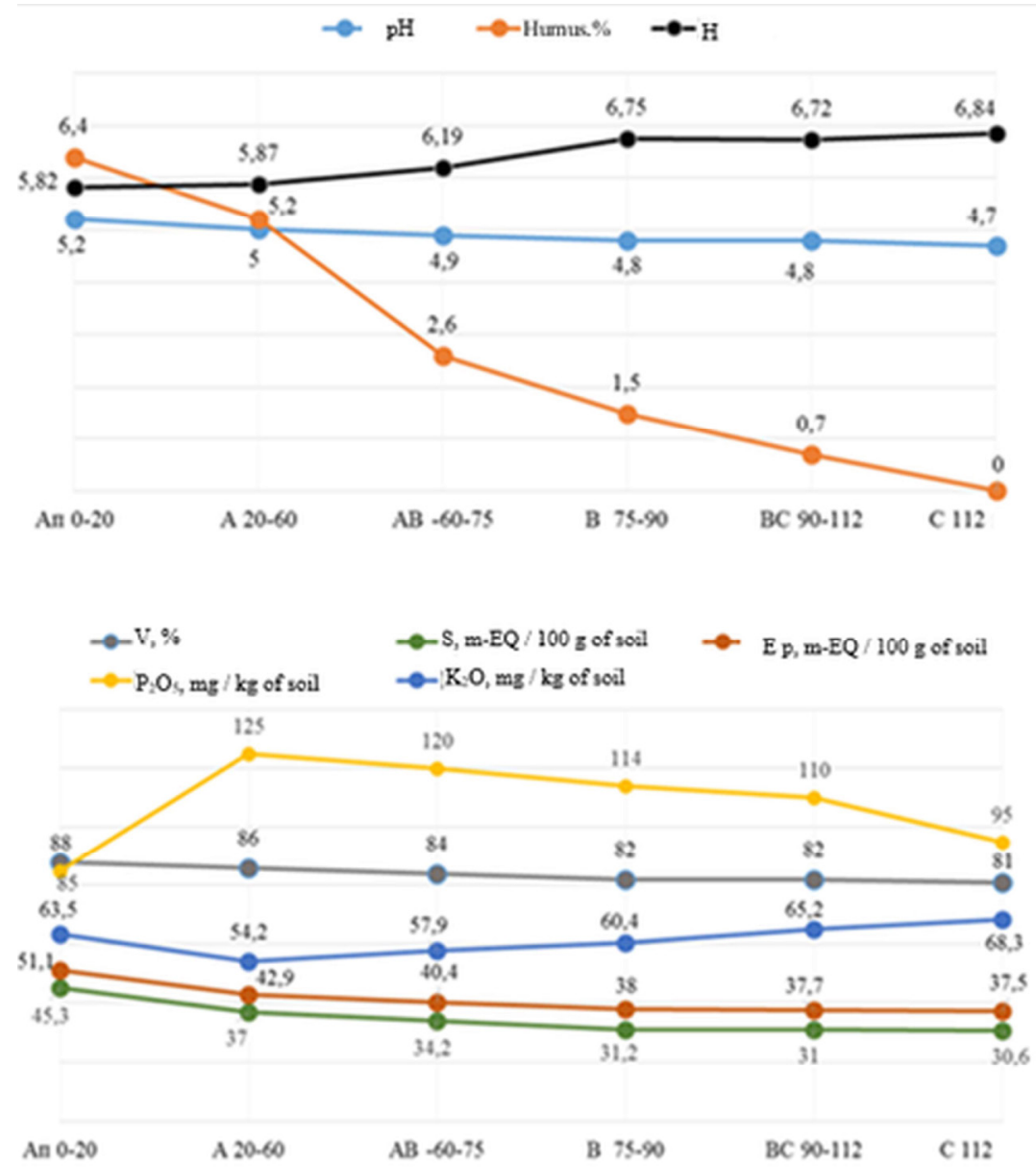

Fig. 1. Agrochemical characteristics of Sartakinsky field soil.

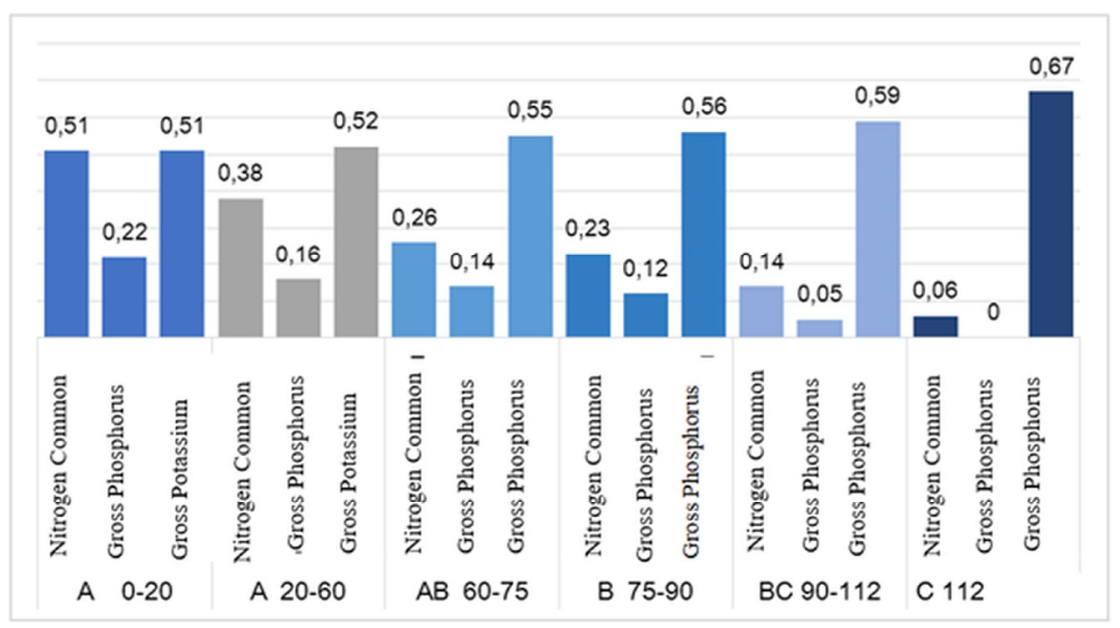

Fig. 2. Content of main mineral nutrition elements of Sartakinsky field soil, \%.

The total calcium and magnesium content ranges from 81 to $88 \%$. The total nitrogen content of the upper horizon is $0.51 \%$. With depth, the total nitrogen content drops markedly. 
There is an increased amount of mobile phosphorus in the upper horizon up to $120 \mathrm{mg} / \mathrm{kg}$. The content of exchange potassium is average throughout the soil profile.

Analysis of physical and chemical characteristics of the Karakansky field. The particle size distribution of the soil of the soil section No.1 of the Karakansky field is represented by loam heavy. The high content of fine sand fraction $-22.4 \%$, coarse dust $-16.8 \%$, silt -22.6 $\%$ is revealed.

Structural units from 5 to $0.25 \mathrm{~mm}$ prevail in the upper horizon structure. Dust accounts for only $5.1 \%$ of the mass of air-dry soil. Significant share of lumpy fraction $(>10 \mathrm{~mm})$ is $28.9 \%$.

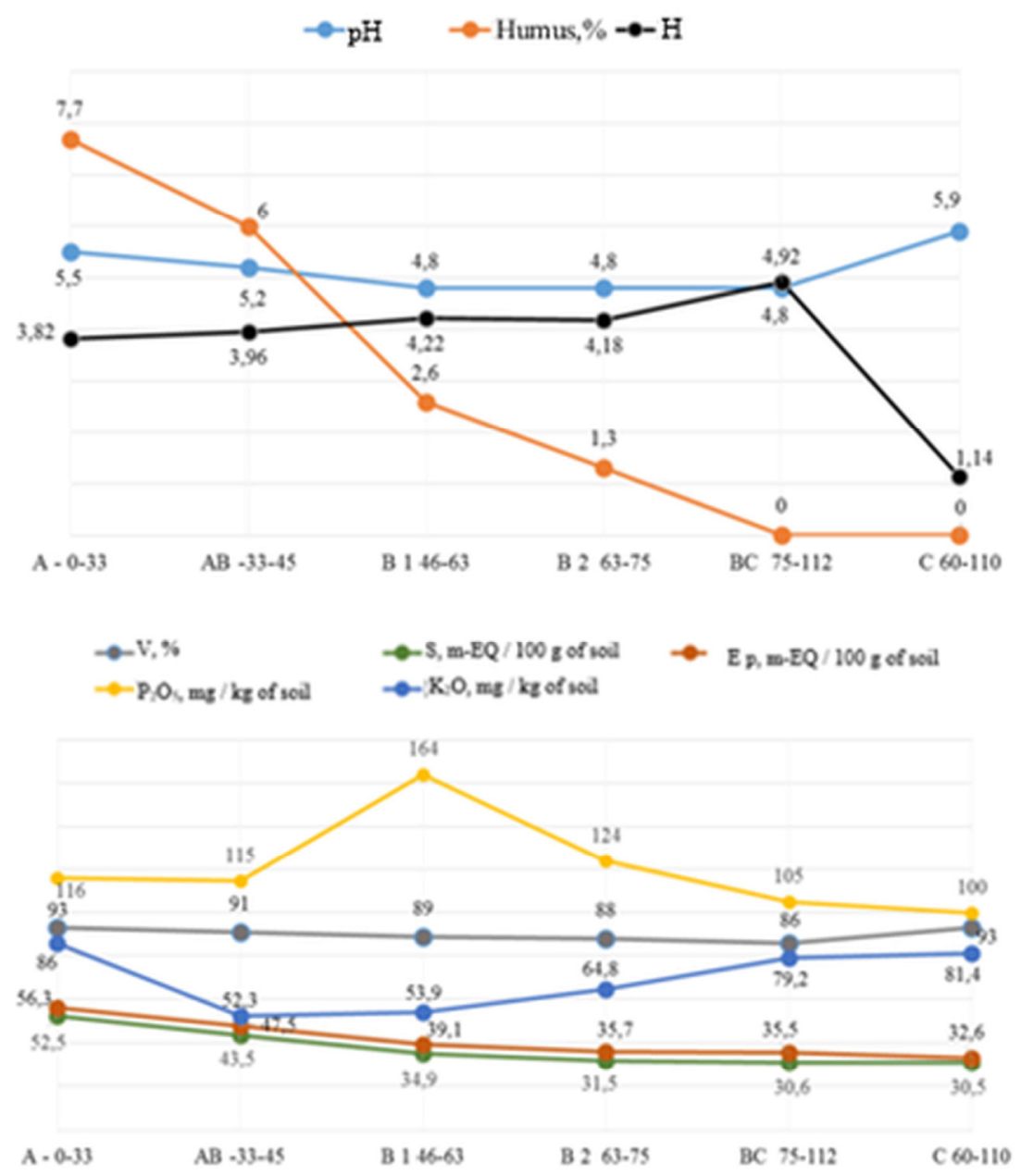

Fig. 3. Agrochemical characteristics of Karakansky field soil.

The humus content of $0-33 \mathrm{~cm}$ layer is high $-7.7 \%$, reducing its values in layer $33-45$ (AB) to only $6.0 \%$. Soil has weakly acidic reaction of soil solution ( $\mathrm{pH} 5.5-5.2)$ in horizons $\mathrm{A}+\mathrm{AB}(0-45 \mathrm{~cm})$, subsequent horizons - medium acid reaction $(\mathrm{pH} 4.8)$.

The sum of absorbed bases of the upper layer - 52,5 mg eq/100 $\mathrm{g}$ - is high, in horizon B - decreases to $43,5 \mathrm{mg}$ eq/100 g. Profile hydrolytic acidity varies from 3.82 to $4.92 \mathrm{mg}$ eq. The total content of calcium and magnesium is $86-93 \%$.

The total nitrogen content of the humus horizon is high and drops sharply with depth. There is an increased amount of mobile phosphorus in the upper horizons up to $116 \mathrm{mg} / \mathrm{kg}$, 
in horizon B1 it reaches $164 \mathrm{mg} / \mathrm{kg}$. The studied samples have average potassium exchange rates.

Analysis of Physical and Chemical Characteristics of Mokhovsky Field. The particle size distribution of the soil composition of the Mokhovsky Field Section No. 1 is represented by a heavy loam. The high content of sand fraction, content of fine sand $23.2 \%$, coarse dust $19,1 \%$ is revealed. Structural aggregates from 5 to $0.25 \mathrm{~mm}$ prevail in the structure of the upper horizon. Dust accounts for only $3.7 \%$ of the mass of air-dry soil. Significant share of lumpy fraction $(>10 \mathrm{~mm})$ is $16.3 \%$.
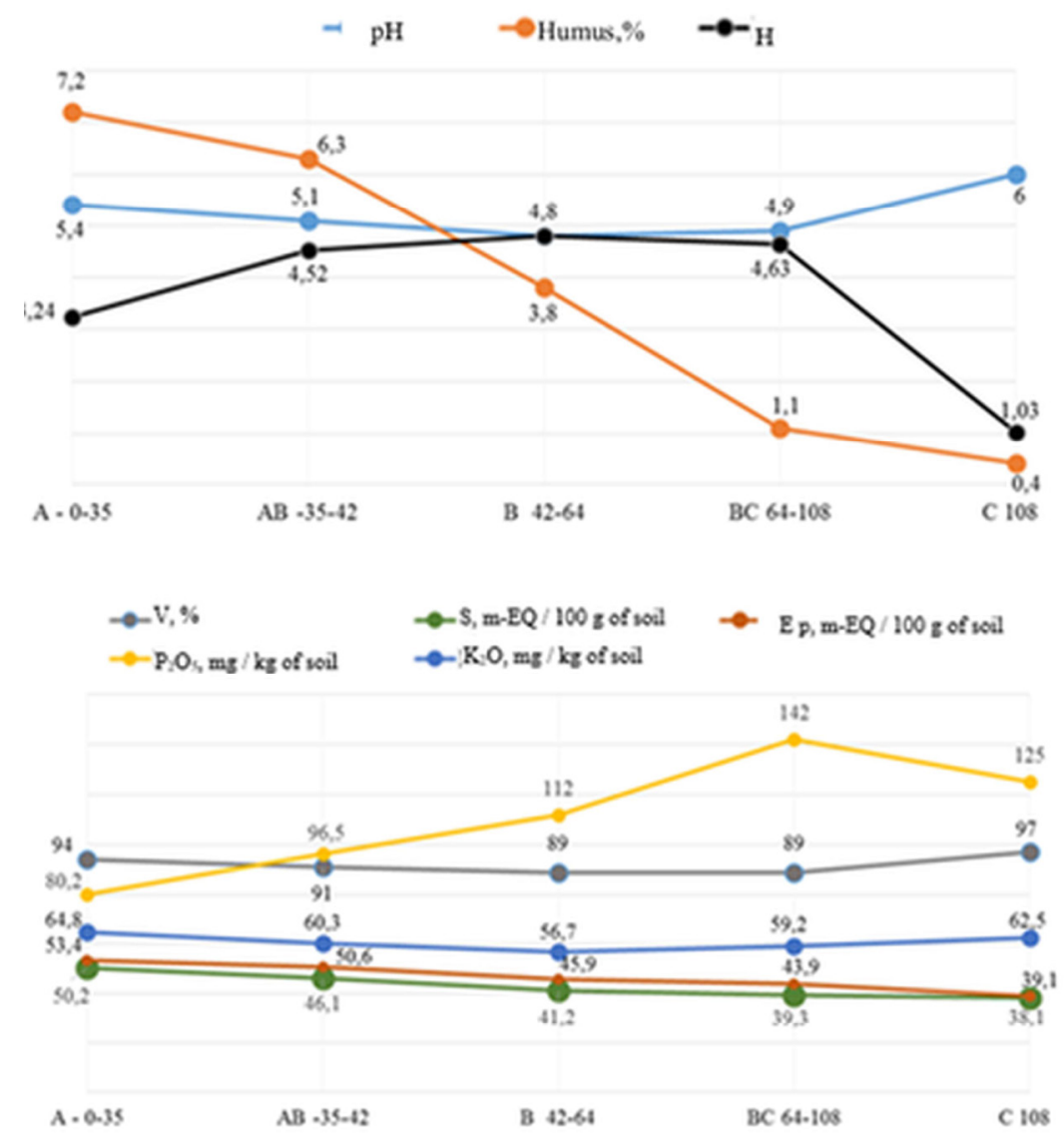

Fig. 4. Agrochemical characteristics of Mokhovsky field soil. 


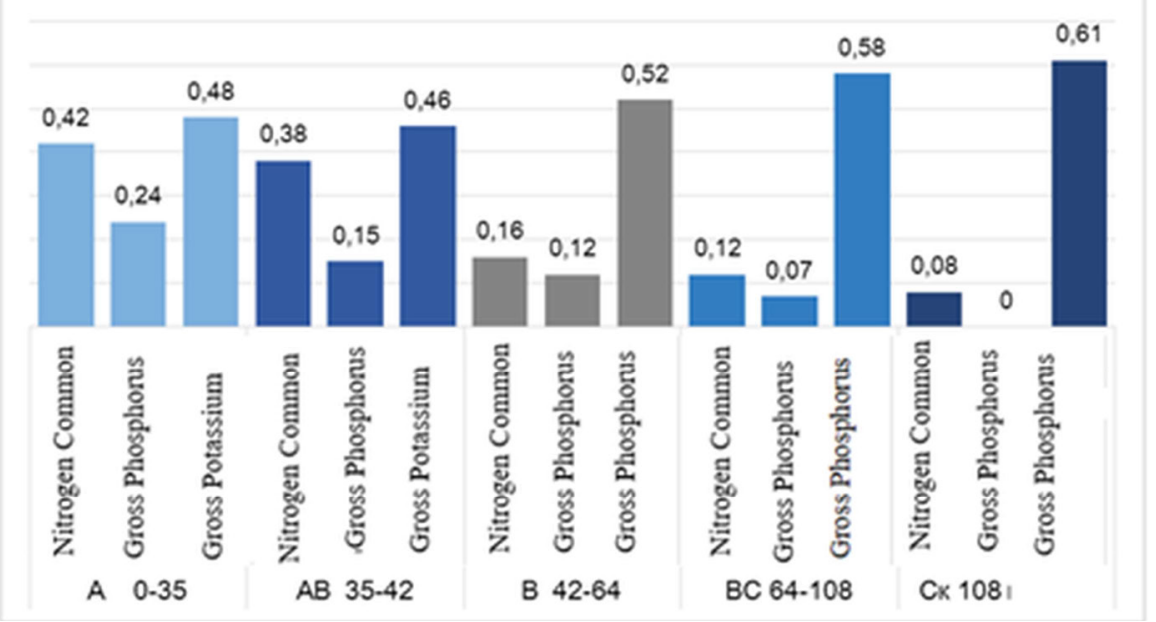

Fig. 5. Content of main elements of mineral nutrition of Mokhovsy field soil, $\%$.

The humus content of the $0-35 \mathrm{~cm}$ layer is high at $7.2 \%$, while that of the $35-42(\mathrm{AB})$ layer is only $6.3 \%$. In the upper horizon of the soil $\mathrm{p}=\mathrm{H} 5.4$, which is indicated by a slightly acidic reaction of the soil solution, in the lower horizons determined the average acidic reaction with $\mathrm{pH}=5.1-4.8$, in the Sk horizon - the reaction is closer to neutral.

There is a high amount of absorbed bases of the upper layer to $50.2 \mathrm{mg} \mathrm{eq} / 100 \mathrm{~g}$, in subsequent layers it decreases to $46.1 \mathrm{mg}$ eq/100 $\mathrm{g}$. The hydrolytic acidity varies in the profile from 3.24 to $4.63 \mathrm{mg} \mathrm{eq} / 100 \mathrm{~g}$, in the Sk horizon it decreases to 1.4. The degree of base saturation in the profile is high, within the range of $89-94 \%$ of the absorption capacity. The content of mobile phosphorus in the upper horizon is average $-80.2 \mathrm{mg} / \mathrm{kg}$. The content of potassium exchange is average throughout the profile.

\section{Conclusions}

Effective reclamation of lands disturbed by mining works is necessary and if it is carried out properly, it is possible to restore the disturbed soils to their previous state. According to the Executive Order of the Ministry of Environmental Protection and Natural Resources of the Russian Federation and the Land Management Committee of the Russian Federation "On Approval of the basic provisions for land reclamation, top-soil stripping, preservation and rational use of the rich soil layer" dated December 22, 1995, the norms for removal of rich soil layer, potentially rich soil layer and rocks are established during the design and determined in accordance with the level of fertility of the disturbed soils, taking into account the relevant guarantees from the consumers for the use of potentially fertile layers and rocks.

The Sartakinsky field of the Mokhovsky coal mine is located on a hollow, lavish plain. The soil cover of the land is represented by podzolic chernozems in a complex up to $25 \%$ with chernozem soils leached heavy loamy. The humus horizon $(A+A B)$ varies from 43 to $75 \mathrm{~cm}$ with humus content of $6.5-5.0 \%$. Analysis of data showed rather high agronomic properties of investigated soils. On all field it is possible to remove and store a rich soil layer $0-40 \mathrm{~cm}$.

The potentially rich soil layer reaches a depth of up to $100 \mathrm{~cm}$ and can be removed and stored. The total volume of rich soil layer and potentially rich soil layer in the Sartakinsky field of the Mokhovsky coal mine is 38.5 thousand cubic meters potentially suitable for removal and storage: rich soil layer - 38.5 thousand cubic meters, potentially rich soil layer 16.5 thousand cubic meters. 
The Karakansky field of the Mokhovsky coal mine of which is represented by chernozem medium-humus-powered heavy loamy black soil is the power of humus horizon $(A+A B)$ up to $45 \mathrm{~cm}$ with the content of humus up to $7 \%$ with weakly acidic reaction of soil solution; in agricultural value the black soils leached are the best soils of the region, belong to the $1 \mathrm{st}$ agricultural production group. Removal of rich soil layer is possible on site \#1 with a layer up to $65 \mathrm{~cm}$, and on site $\# 2$ - up to $40 \mathrm{~cm}$. Removal of rich soil layer is possible up to 100 $\mathrm{cm}$.

The Mokhovsky Field of the Mokhovsky coal mine is located on the hollow lavish plain of the northern exposition. The soil cover of the land is represented by chernozem soils plumed. The thickness of humus horizon $(\mathrm{A}+\mathrm{AB})$ varies from 42 to $55 \mathrm{~cm}$. Soil cover of the land is represented by chernozem soils medium-humus in complex up to $25 \%$ with chernozem soils low-power heavy loamy.

The researched soils have rather high agronomic properties. It is possible to remove and store a rich soil layer (PSP) 0 - $40 \mathrm{~cm}$ throughout the field. The total volume of rich soil layer and potentially rich soil layer in the Mokhovsky field of the Mokhovsky coal mine potentially suitable for removal and storage: rich soil layer - 302 thousand cubic meters, potentially rich soil layer - 308 thousand cubic meters.

Thus, the soil cover of the fields of the Mokhovsky coal mine in the Kemerovo region is represented by a diverse list of lands with high natural fertility. It is possible to further use the soil cover in the national economy in order to improve the quality, productivity and environmental value of the lands being restored.

\section{References}

1. O. I. Prosiannikova, Anthropogenic transformation of the Kemerovo region soils: monograph (Kemerovo: Kemerovo State Agricultural Institute, 2005)

2. O. Micanova, Utilization of Microbial Inoculation and Compost for Revitalization of Soils, 1, 126-130 (2009)

3. M. A. Yakovchenko, IOP Conf. Series: Materials Science and Engineering, 91 (2015) DOI:10.1088/1757-899x/91/1/012078

4. A. N. Blepov, Coal, 4 (2019)

5. I. V. Zenkov, Coal, 4 (2019)

6. I. V. Zenkov, Coal, 9 (2019)

7. J.J. Ibanez Future of soil science, 4, 60-62 (2006)

8. M. Pietrzykowski, Science of the Total Environment, 7, 470-471 (2014)

9. L. Rủžek Chemical and biological characteristics of reclaimed soils in the Most region (Czech Republic) / Plant Soil Environ., 49(8), 346-351 (2003)

10. Z. Zhonqiu, European Journal of Soil Biology, 55, 90 (2013)

11. M.J. Blaylock, Environ. Sci. Technol, 31(3), 860-865 (1997)

12. J. Remes, Journal of Forest Science, 51, 299-307 (2007)

13. M. Pietrzykowski, Journal of Forest Science, 54, 554-565 (2008) 